\title{
PERIANAL COMPLETE REMISSION WITH COMBINED THERAPY (SETON PLACEMENT AND ANTI-TNF AGENTS) IN CROHN'S DISEASE: a Brazilian multicenter observational study
}

\author{
Paulo Gustavo KOTZE 1 , Idblan Carvalho de ALBUQUERQUE², André da Luz MOREIRA ${ }^{3}$, \\ Wanessa Bertrami TONINI ${ }^{1}$, Marcia OLANDOSKI $^{1}$ and Claudio Saddy Rodrigues COY$^{4}$
}

\begin{abstract}
Background - Perianal fistulizing Crohn's disease is one of the most severe phenotypes of inflammatory bowel diseases. Combined therapy with seton placement and anti-TNF therapy is the most common strategy for this condition. Objectives - The aim of this study was to analyze the rates of complete perianal remission after combined therapy for perianal fistulizing Crohn's disease. Methods - This was a retrospective observational study with perianal fistulizing Crohn's disease patients submitted to combined therapy from four inflammatory bowel diseases referral centers. We analyzed patients' demographic characteristics, Montreal classification, concomitant medication, classification of the fistulae, occurrence of perianal complete remission and recurrence after remission. Complete perianal remission was defined as absence of drainage from the fistulae associated with seton removal. Discussion - A total of 78 patients were included, $44(55.8 \%)$ females with a mean age of $33.8( \pm 15)$ years. Most patients were treated with Infliximab, 66.2\%, than with Adalimumab, 33.8\%. Complex fistulae were found in 52/78 patients (66.7\%). After a medium follow-up of 48.2 months, $41 / 78$ patients ( $52.6 \%$ ) had complete perianal remission (95\% CI: 43.5\%-63.6\%). Recurrence occurred in four $(9.8 \%)$ patients (95\% CI: $0.7 \%-18.8 \%)$ in an average period of 74.8 months. Conclusion - Combined therapy lead to favorable and durable results in perianal fistulizing Crohn's disease.
\end{abstract}

HEADINGS - Crohn's disease. Tumor necrosis factor-alpha. Rectal fistula.

\section{INTRODUCTION}

Perianal fistulizing Crohn's disease (PFCD) is one of the most aggressive and disabling phenotypes of this important subtype of inflammatory bowel diseases (IBD) ${ }^{(10)}$. Complex and simple fistulas can affect the perianal area in $25 \%$ to $80 \%$ of Crohn's disease (CD) patients, and are related to significant symptoms such as purulent discharge, local oedema, soiling and anal discomfort ${ }^{(24)}$. Young patients can be often affected by PFCD, with consequent decreased quality of life, mainly related to limitations in daily and sexual activities.

Complementary tests such as endorectal ultrasound, pelvic magnetic ressonance imaging (MRI) and examination under anesthesia (EUA) lead to nearly $100 \%$ of accuracy in the diagnosis of the fistula tracks, mainly when used as concomitant diagnostic tools ${ }^{(3)}$.

Medical therapy in isolation for PFCD is associated with significant limitations, mainly in conventional treatment. Antibiotics such as metronidazole and ciprofloxacin can be used with variable success rates, but recurrence is quite frequent after treatment discontinuation, that can occur due to important adverse events ${ }^{(4,21)}$. Immunomodulators (azathioprine or 6-mercaptopurine) also can lead to reduction of purulent discharge, and are often used in clinical practice $^{(15)}$. However, clinical data from prospective trials are scarce and limited with these agents ${ }^{(14)}$.

The use of tumor-necrosis-factor antagonists (anti-TNF agents), like Infliximab (IFX) ${ }^{(16,19)}$ and Adalimumab (ADA) ${ }^{(5)}$, can lead to an improve of the inflammation of perianal fistulas related to $\mathrm{CD}$. One

Disclosure: Paulo Gustavo Kotze is a speaker and consultant for Abbvie, Janssen-Cilag, Ferring, Astrazeneca and Takeda. He is also consultant and did clinical research for Pfizer and received scientific support from Ethicon. André da Luz Moreira and Claudio Saddy Rodrigues Coy: speakers for Abbvie Laboratories. Idblan Carvalho de Albuquerque: speaker for Abbvie and Janssen-Cilag.

Research performed at: Unidade de Cirurgia Colorretal, Hospital Universitário Cajuru, Universidade Católica do Paraná - PUCPR, Curitiba, PR

Unidade de Cirurgia Colorretal, Hospital Universitário Cajuru, Universidade Católica do Paraná - PUCPR, Curitiba, PR. ${ }^{2}$ Unidade de Doencas Inflamatórias Intestinais, Hospital Heliópolis, São Paulo, SP; ${ }^{3}$ Unidade de Cirurgia Colorretal, Universidade do Estado do Rio de Janeiro - UERJ, Rio de Janeiro, RJ; ${ }^{4}$ Unidade de Cirurgia Colorretal, Universidade de Campinas - UNICAMP, Campinas, SP. Brasil.

Correspondence: Paulo Gustavo Kotze. Rua Mauá, 682. CEP: 80030-200, Curitiba, PR, Brasil. E-mail: pgkotze@hotmail.com 
study even demonstrated that the association of ADA with ciprofloxacin had lead to better results than the use of ADA as monotherapy ${ }^{(6)}$. These drugs were studied in some prospective trials, and up to date, anti-TNF agents seem to be the most powerful medications in the management of this phenotype of $\mathrm{CD}^{(5,6,16,19)}$, when properly indicated. However, some retrospective populational studies had demonstrated that in the biological era, there was an increase in the occurrence of perianal abscesses with biological agents alone, possibly due to the closure of the external openings at the skin level, with persistence of the inflammatory process at the fistula tracks ${ }^{(11)}$.

Surgical procedures, in isolation or combined with conventional therapy (immunomodulators or antibiotics), can also improve the inflammation on the perineum of these patients, although there are clear limitations in the results of the studies previously published ${ }^{(18)}$. Fistulotomies are often an adequate way of treating superficial intersphincteric fistulas. Advancement flaps can also heal the fistulas in CD patients, mainly in the absence of active proctitis ${ }^{(12)}$.

Combined therapy with anti-TNF agents and seton placement during EUA seems to be the most effective form of treatment of $\mathrm{PFCD}^{(2,7,8)}$. The curettage of the fistula tracks associated with the economic excision of the inflammed external openings prepare the perianal tissue for the proper action of biological agents. Regueiro et al. have studied the efficacy of IFX in PFCD, and demonstrated that the healing rates were higher and recurrence rates were lower when the biological agent was associated with seton placement, as compared to its use in isolation ${ }^{(17)}$. Gaertner et al. also demonstrated similar results, showing $42 \%$ of healing rates in patients treated with seton placement associated with IFX, a higher index as compared to surgery alone $(18 \%)^{(8)}$.

There are several outcomes to be achieved as a result of the approach to PFCD described in the literature, as a reduction of $50 \%$ of fistula drainage, closure of external fistulas and complete healing ${ }^{(8,16,19)}$. Some patients remain well even maintaining their setons during biological therapy. Few case series had studied the outcome of complete perianal remission, with abscence of drainage and withdrawal of the setons, with a completely healed perineum.

The aim of this study was to check the rates of perianal complete remission in a case series of PFCD Brazilian patients, previously submitted to combined therapy (seton placement during EUA followed by anti-TNF induction and maintenance therapy). Secondary objectives were to analyze the presence of recurrence of active PFCD after remission, and the timing for its occurrence.

\section{METHODS}

\section{Study design}

This was a retrospective observational study, with consecutive patients from four referral IBD units in Brazil, submitted to combined therapy for PFCD, treated between January 2005 and November 2011, followed until July 2012. The analysis was performed with a complete electronic chart review after identification of the patients from operating lists from the referral units. Data was fulfilled by four different physicians, according to an established protocol. The analysis did not use any control group to compare the variables.

\section{Inclusion and exclusion criteria}

In this study, we included patients with $\mathrm{CD}$ at any age, diagnosed by clinical symptoms and imaging tests, associated with endoscopic examinations with biopsies. Patients with PFCD (with simple or complex fistulas), that were treated with EUA, seton placement and subsequent anti-TNF therapy (IFX or ADA) initiation, with induction followed by maintenance regimen, were included in this analysis.

Patients with missing data in the charts, with non-fistulizing perianal CD (skin tags, fissures and hemorrhoids, for example), submitted to other perianal procedures (fistulotomies for superficial fistulas or advancement flaps) or patients that were treated with medical therapy in isolation (with antibiotics or immunomodulators) were excluded from this analysis. Patients with recto-vaginal fistulas and with anti-TNF therapy administered before the surgical procedures were also excluded.

\section{Demographics and clinical variables}

The clinical variables analyzed were: demographic data (age at the beggining of the treatment, genre), Montreal classification, concomitant medication at combined therapy initiation (steroids or immunomodulators), type of perianal fistula (simple or complex), time of follow-up, number of EUA performed during combined therapy, seton withdrawal (if performed, the timing of its occurrence), presence of complete perianal remission, presence and timing of recurrence. The fistulae were classified as simple or complex based on the American Gastroenterological Association classification, published in $2003^{(1)}$. Fistulae were considered simple when a lower track was found (intersphincteric, for example), with a single external opening, no complications as abscesses and strictures, without active proctitis. On the other hand, they were considered complex when a higher track was identified (suprasphincteric, for example), with multiple external openings, possibly associated with stenosis, abscesses and active proctitis.

\section{Patients protocol}

All patients from the four referral IBD units were treated with combined therapy. They were submitted to EUA (with general or spinal anesthesia), the fistula tracks were explored and a simple curettage was performed, associated with excision of external openings when needed. Rubber-made setons were passed through the tracks with fixation by the overlapping technique, performed with simple knots of doubled 0 cotton strings (Figure 1).

After EUA and seton placement, the type of agent (IFX or ADA) was chosen in accordance to a patient and physician consensus, and anti-TNF therapy was initiated. IFX was initiated with the regular induction regimen of intravenous $5 \mathrm{mg} / \mathrm{kg}$ in weeks 0,2 and 6 , followed by maintenance infusions with the same dose every 8 weeks. ADA induction was performed with subcutaneous injections of $160 \mathrm{mg}$ at week 


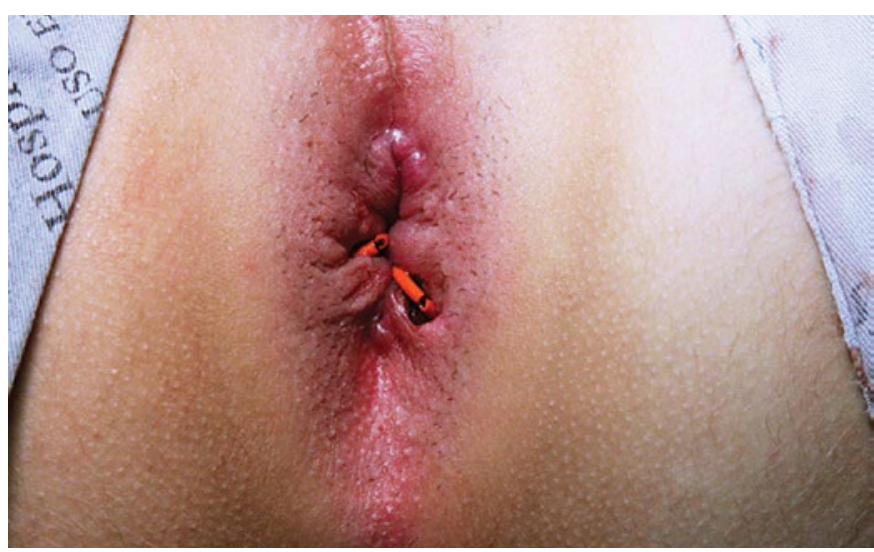

FIGURE 1. Seton placed (red), fixation with overlapping technique with simple strings knots (black).

$0,80 \mathrm{mg}$ at week 2 and $40 \mathrm{mg}$ every other week after week 4 . The initiation of biological therapy with both agents could occur right after the EUA (in the same admission) until 14 days after seton placement. All patients included did not use previously any anti-TNF agent (they were naïve to biological therapy). During anti-TNF therapy, the patients could be treated with concomitant immunomodulators such as azathioprine or 6-mercaptopurine, or with biological monotherapy. All patients used antibiotics for at least 2 weeks after the EUA and anti-TNF initiation.

Patients were then followed in outpatient setting, and could have their setons removed according to individual case-based decisions, mainly after rigid proctoscopies that demonstrated abscence of rectal inflammation. This seton removal could be performed any time during the follow-up visits. Patients were allowed to maintain their setons, if that was their option. Additional EUA and curettage of the fistula tracks could be performed according to the surgeon's perception of indication.

\section{Outcome measurement and defi nitions}

The primary objective of this study was to evaluate the rates of complete perianal remission, which was defined as complete absence of perianal drainage from fistula tracks with gentle finger pressure, associated with seton withdrawal (complete closure of all fistula tracks, without setons). Patients that had absence of drainage that wanted to keep their setons in place were allowed to maintain them, but were considered as having not achieved this outcome. These were considered to have remission with setons (partial response). The others that had still persistance of drainage with setons, were considered to have active PFCD.

Secondary objectives were to analyze recurrence rates in the patients that achieved complete perianal remission, and the timing for its occurrence. Recurrence was defined as reactivation of previous healed tracks, (recurrent drainage after complete perianal remission), the need for subsequent seton placement performed in EUA, due to new fistulas or or the occurrence of perianal abscesses after healing during the follow-up period.

\section{Statistical analysis}

Demographic data was described in frequency tables, and the occurrence of perianal complete remission was analyzed with Confidence intervals (CI) of $95 \%$. Log-rank analysis was performed to check the recurrence rates, as well as the Kaplan-Meier method in relation to the timing of its occurrence. These analysis were performed with the software Statistica package, version 8.0.

\section{Ethical considerations}

This study was previously approved by the Ethics Research Committee of the Catholic University of Paraná, under reference number 11909/2012, via the central website from the Brazilian ministry of health (Plataforma Brasil). There was no need for informed consent, as data was retrospectively gathered from eletronic charts.

\section{RESULTS}

\section{Patients' characteristics}

Initially, 83 consecutive patients with PFCD, in the period of the study, were identified after perianal procedures. From those, five were excluded from the analysis as they had primary fistulotomies performed, due to superficial intersphincteric fistulas, instead of EUA with seton placement. Overall, the study sample was composed of 78 PFCD patients that fulfilled the inclusion criteria.

The baseline characteristics of the 78 patients are described in Table 1 . The population of the study was mostly

TABLE 1. Baseline characteristics of the 78 patients enrolled in the analysis

\begin{tabular}{ll}
\hline Demographics & $33.8(2-80)$ \\
Median age at first EUA (years) & $34(44.2 \%)$ \\
Male gender (n/\%) & $44(55.8 \%)$ \\
Female gender (n/\%) & $88.9(0-300)$ \\
CD duration at first EUA (months) & $48.2(2-228)$ \\
Mean Follow-up (months) & \\
Montreal classification (n/\%) & $17(21.8 \%)$ \\
A1 & $39(50 \%)$ \\
A2 & $22(28.2 \%)$ \\
A3 & $11(14.1 \%)$ \\
L1 & $6(7.7 \%)$ \\
L2 & $61(78.2 \%)$ \\
L3 & $0(0 \%)$ \\
L4 & $32(41 \%)$ \\
B1 & $20(25.7 \%)$ \\
B2 & $26(33.3 \%)$ \\
B3 & $78(100 \%)$ \\
Perianal CD & \\
Smoking and medications (n/\%) & $8(10.3 \%)$ \\
Smoking & $60(76.6 \%)$ \\
Concomitant azathioprine & $26(33.3 \%)$ \\
Steroids at first EUA & \\
Type of fistulas (n/\%) & $26(33.3 \%)$ \\
Simple & $52(66.7 \%)$ \\
Complex & \\
Biological agent used (n/\%) & $49(62.8 \%)$ \\
IFX & $29(37.2 \%)$ \\
ADA &
\end{tabular}

CD: Crohn's disease; IFX: Infliximab; ADA: Adalimumab. 
composed by young patients, with primary ileocolic and penetrating $\mathrm{CD}$ (Montreal classification A2, L3 and B1 were the most common characteristics observed). It was also noteworthy that the vast majority of the patients had complex fistulas and were treated with IFX (2/3 of our sample for each variable). The mean follow-up period of the study was 48.2 months (2-228).

\section{Surgical characteristics}

The number of EUA with seton placements varied from 1 to 12 (median number 2.7) per patient, with the majority of patients (aproximately 60\%) having one or two procedures during follow-up (Table 2). Moreover, the number of setons placed per patient varied from one to seven (median number two per patient), with the majority of patients (aproximately $77 \%$ ) having one or two setons placed (Table 3). From the 51 patients that have their setons removed, the average time for seton withdrawal was 7.3 months (1-36 months, $\mathrm{SD}=6.4)$. Only 41 of them presented with perianal complete remission, and 10 persisted with active discharge from the fistulas after seton withdrawal. This means that
27 patients did not have their setons removed, mainly for patient's option or physicians' decision (presence of active purulent discharge). Figure 2 demonstrates a patient with complete perianal remission.

\section{Primary objective - perianal complete remission}

From the 78 patients included, $41(52.6 \%)$ presented complete perianal remission (complete healed perineum, without active fistulas, drainage or setons). The remaining 37 patients $(47.4 \%)$ were considered to have active disease $(\mathrm{n}=29)$ or partial response (absence of fistula drainage but persistence of the seton as a patient's option) $(n=8)$. These results are demonstrated in Figure 3.

\section{Recurrence}

Recurrence was observed in only four patients of the 41 that presented complete perianal remission $(9.8 \%$ of the cases; $95 \%$ C.I. $0.7 \%$ - $18.8 \%$ ). The average period for its occurrence was 74.8 months. The Kaplan-Meier curve in Figure 4 demonstrates the cumulative proportion of recurrence. It is clear that on the median follow-up of 4 years observed in the

TABLE 2. Number of setons placed per patient, time for seton withdrawal and number of EUA per patient. EUA: examination under anesthesia

\begin{tabular}{lcccccc}
\hline Variable & $\mathbf{n}$ & Average & Median & Minimum & Maximum & Standard deviation \\
\hline Number of setons & 78 & 2.0 & 1.0 & 1.0 & 7.0 & 1.4 \\
Time for seton withdrawal (months) & 51 & 7.3 & 6.0 & 1.0 & 36.0 & 6.4 \\
Number of EUA per patient & 78 & 2.7 & 2.0 & 1.0 & 12.0 & 2.3 \\
\hline
\end{tabular}

TABLE 3. Number of setons placed per patient, with correspondent percentages

\begin{tabular}{lcc}
\hline $\begin{array}{l}\text { Number of setons } \\
\text { placed per patient }\end{array}$ & Patients (n) & Frequency (\%) \\
\hline 1 & 41 & 52.6 \\
2 & 19 & 24.4 \\
3 & 8 & 10.3 \\
4 & 3 & 3.8 \\
5 & 5 & 6.4 \\
6 & 1 & 1.3 \\
7 & 1 & 1.3 \\
Total & 78 & 100.0 \\
\hline
\end{tabular}

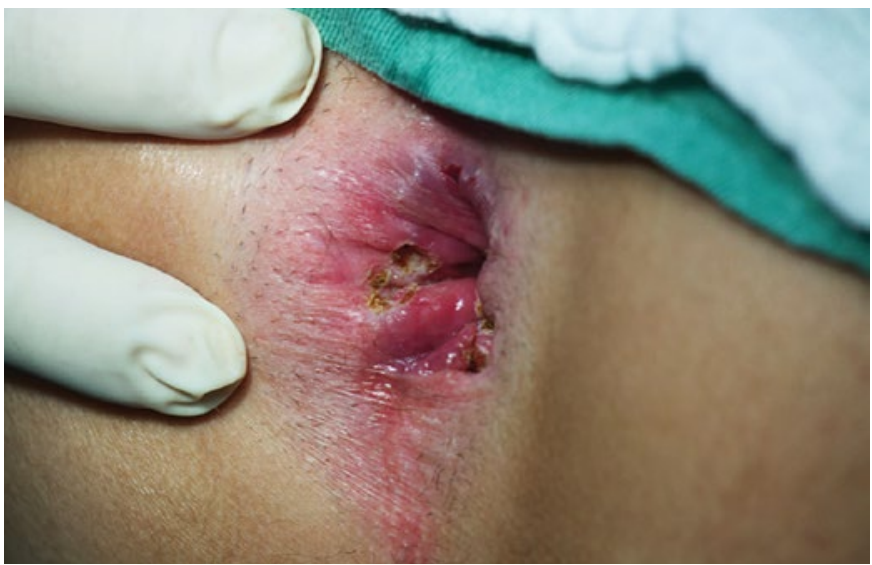

FIGURE 2. Patient examination after combined therapy, with complete perianal remission. Immediate postoperative aspect after last examination under anesthesia.

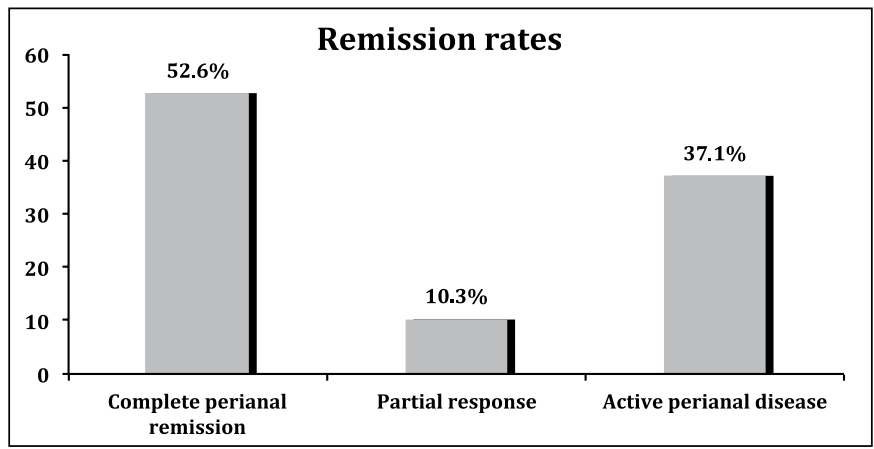

FIGURE 3. Primary objective of the study. Perianal complete remission (defined as absence of drainage and seton withdrawal) was observed in $52.6 \%$ of the patients.

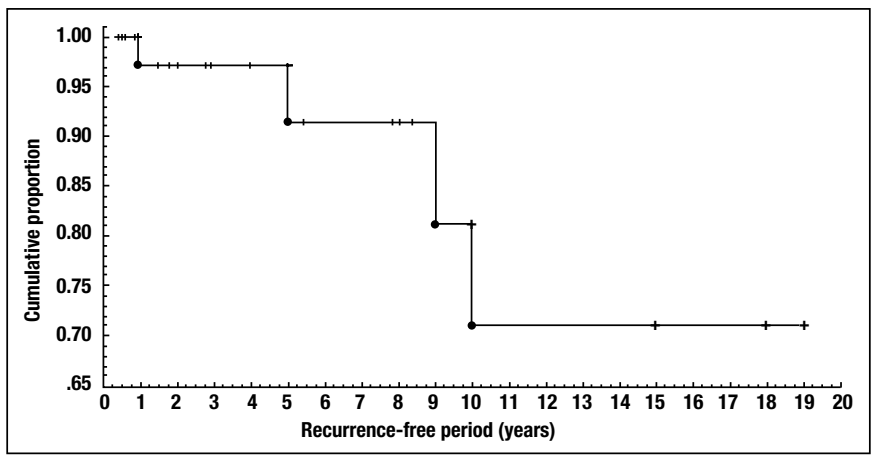

FIGURE 4. Kaplan-Meier curve demonstrating recurrence rates after perianal complete remission, observed in $4 / 41(9.8 \%)$ patients (95\% C.I. $0.7-18.8)$. 
study, approximately $97 \%$ of the patients tended to maintain perianal complete remission.

\section{DISCUSSION}

Perianal fistulas still remain one of the most challenging forms of Crohn's disease, even with the significant advances in medical therapy that occurred in the last 15 years. Most of the data in the literature are based on non-randomized trials, and clinical practice has been driving the management of this phenotype of CD more recently ${ }^{(22)}$.

Data regarding direct comparison of different treatment strategies in PFCD are limited. Most of the studies with conventional therapy, such as antibiotics and immunomodulators, were based on observational case series, and the few randomized trials were performed in small samples, with conflicting results ${ }^{(4,14,15,21)}$. However, even with significant methodological biases from these previous experiences, there is almost a consensus that medical or surgical therapy in isolation present limited results in the management of PFCD. The concept of combined therapy between medications and different surgical techniques was developed during the last decades, and is the most common strategy performed nowadays ${ }^{(22)}$.

The classification of perianal fistulas in $\mathrm{CD}$ (in the present study, based on the AGA technical note, that divides the fistulas in simple or complex) is essential to select the patients that would benefit from a combined approach with surgery and anti-TNF agents. This classification is widely used due to its simplicity and easiness of appliance in daily clinical practice ${ }^{(1)}$.

The management of PFCD with combined therapy (anti-TNFs and seton placement) is not needed in every patient with perianal fistulas in CD. The European Crohn's and Colitis Organisation (ECCO) guidelines even describe anti-TNF agents as a second line medical therapy after $\mathrm{EUA}^{(22)}$. Patients with superficial intersphincteric fistulas can be easily submitted to fistulotomies associated with conventional medical therapy (antibiotics or immunomodulators) with favorable results. That was observed in five patients of our study's population, that were excluded from the main analysis. These kind of patients do not need to initiate biological therapy, with the risk of overtreatment, potential adverse events and increased costs.

Therefore, the classification of the type of the fistulas is extremely important in order to identify properly the patients with complex fistulas, with concomitant proctitis, that will have their treatment to be directed towards an anti-TNF agent after the surgical procedure. Complementary tests such as MRI and endorectal ultrasound, associated with EUA, can help to better identify these patients, that are ideal candidates for the combined approach.

The treatment target of PFCD is variable on several studies from the literature. In a study to verify the efficacy of IFX in the management of complex fistulas, Present et al. aimed to check a reduction in $50 \%$ of the drainage from the fistula tracks ${ }^{(16)}$. In the ACCENT II study, equally per- formed with IFX, the primary objective was the same ${ }^{(19)}$. Other studies aimed to verify a reduction in the number of fistulas after therapy. The target of "complete healing" of the fistulas is also limited by the fact that even after the absence of drainage of the fistulas, MRI can identify the presence of active inflammation inside the tracks, which means that even with absence of drainage, the fistulas could be not actually healed ${ }^{(23)}$

In this scenario of heterogeneous objectives with significant limitations in the definition of the proper target, the objective of our study was to identify patients without active drainage associated with seton withdrawal, and that was defined as perianal complete remission. That means that patients could even have active disease elsewhere in the digestive track, after achievement of complete remission of the perianal fistulas. We believe that this could be the best outcome to be identified in an observational retrospective case series. Talbot et al., classified the results after therapy in complete, partial or absent response ${ }^{(20)}$. Hyder et al., aimed a reduction in the Perianal Crohn's disease Activity Index (PDAI), a more objective measurement that was not used in our study due to its retrospective design ${ }^{(9)}$. Other interesting studies had demonstrated that an objective measurement of inflammation in the perianal fistulas with MRI can be more precise, and maybe this can be better studied in a prospective future trial ${ }^{(13)}$. No patients from the present study's sample was submitted to MRI after the procedures, to check inflammation.

The association of antibiotics with combined therapy is another important theme of debate in the management of PFCD. Some studies demonstrated the results of case series of patients that used antibiotics (ciprofloxacin or metronidazole) for 1 or 2 weeks after the first IFX infusion ${ }^{(2,7,8)}$. One prospective study even demonstrated that the association of ciprofloxacin for 12 weeks with ADA had lead to better results than monotherapy with ADA in this scenario ${ }^{(6)}$. In the present study, we did not look for the use of concomitant antibiotics after surgery in the long term. All patients included had used metronidazole or ciprofloxacin for at least a short period after the procedures ( 2 weeks). A future prospective trial would had to include the strategy of combined antibiotics with anti-TNFs after the EUA, according to the previous experience from the ADAFI study ${ }^{(6)}$.

Complete perianal remission was found in $52.6 \%$ of our patients. This number is similar to the rates found in the literature, in retrospective studies. Talbot et al. described $47 \%$ of complete response to the treatment ${ }^{(20)}$, and Gaertner et al., in the subgroup that received IFX after seton placement, described aproximately $42 \%$ of complete healing, in 112 patients ${ }^{(8)}$. On the other hand, Antakia et al. demonstrated a $29 \%$ rate of complete response and $42 \%$ of partial remission in a sample of 48 patients $^{(2)}$. Hyder et al. described only $18 \%$ of sustained fistula healing, maybe due to the short follow-up period in their study ${ }^{(9)}$. Our favorable results can be really considered, as compared to other studies, due to the longer follow-up period and also to the individualized strategy that was undertaken, regarding the seton withdrawal in an 
optimal timing as well as a repetition of the EUA whenever needed according to the surgeon's decision. This tight control individualized strategy can justify our rates of complete perianal remission, that could be even underestimated, mainly due to the fact that patients without active drainage that wanted to keep their setons were allowed to do it (incomplete remission), what may had lowered the rates of success.

Recurrence occurred in only four of the 41 patients that had achieved perianal complete remission $(9.8 \%)$ during a median follow-up of approximately 4 years. Data from previous studies regarding recurrence are quite heretogeneous, and difficult to interpret, mainly because of different study designs and different surgical strategies. Antakia et al. described $25 \%$ of reccurrence after total remission, and $45 \%$ in partial responders, in a median follow-up of 20 months $^{(2)}$. Talbot et al. described no recurrence in the 10 patients with total remission, with a similar follow-up period ${ }^{(20)}$. The durable maintenance of complete perianal remission with low recurrence rates in our study can be justified by the previous imaging tests in all patients, that helped to better identify secondary hidden fistula tracks. This strategy probably reduced the rates of perianal abscesses after the first EUA, that could occur in a significant portion of patients with occult fistula tracks. Moreover, the possibility to repeat the EUA when needed and the seton withdrawal being mostly performed later on during the follow-up also contributed to our low recurrence rates. No patients in our population had to undergone to proctectomy during follow-up.

Two previous retrospective studies decided to perform seton withdrawal after two IFX infusions ${ }^{(2,9)}$. That was not the strategy in our study, and there is no consensus on the proper timing for that therapeutical step. The decision of the proper timing of seton withdrawal was based on the surgeons' perception of active drainage and active proctitis, and was not standardized. The average period for withdrawal of the setons was 7.3 months, varying from 1 to 36 months. Moreover, the number of sequential EUA performed was equally different from other studies. In our observational case series, the average number of surgical procedures was 2.7 (varying from 1 to 12). We believe that the timing of seton withdrawal and the number of procedures during combined therapy are other controversial issues that need to be better studied in future prospective trials.

Our study had clear limitations, mainly due its retrospective, observational and multicentric design. Additionally, the patients did not have exactly the same treatment during follow-up. The variable number of EUA, and the individualized decision of the proper timing of seton withdrawal could possibly have made this sample heterogeneous in some aspects. Moreover, we did not perform MRI tests after the procedures, in order to check active inflammation inside the fistula tracks before seton withdrawal. Perianal fistulas compose a very heterogeneous phenotype of $\mathrm{CD}$. Therefore, it is very difficult to standardize the therapy for every patient.

In summary, in this multicenter observational study, perianal complete remission was observed in $52.6 \%$ of PFCD patients submitted to combined therapy, with EUA and seton placement followed by anti-TNF therapy with IFX or ADA, and only $9.8 \%$ of these patients developed recurrence. The findings of our study, that must be interpreted with caution, suggest that the combination of seton placement with subsequent anti-TNF therapy lead to favorable and durable results in a significant proportion of patients. Individualized case-to-case based decisions, mainly regarding the optimal timing for seton withdrawal, and the possibility to repeat the EUA whenever needed, are possible reasons for the promising results achieved in this case series, and can be better studied in future prospective trials.

\section{ACKNOWLEDGEMENTS}

The authors would like to acknowledge the library personnel from the Cajuru University Hospital (for the help with the referenced articles). PK, AM, IA and CC designed the study, did data collection and analyses and drafted the manuscript. WT did data collection. MO performed the statistical analysis. All authors read and approved the final manuscript.

Kotze PG, Albuquerque IC, Moreira AL, Tonini WB, Olandoski M, Coy CSR. Remissão perianal completa com terapia combinada (sedenhos e agentes biológicos) na doença de Crohn: um estudo brasileiro observacional e multicêntrico. Arq Gastroenterol. 2014,51(4):283-9.

RESUMO - Contexto - A doença de Crohn perianal fistulizante é uma das formas mais graves das doenças inflamatórias intestinais. A terapia combinada com sedenhos e agentes biológicos é a estratégia mais comumente empregada para essa condição. Objetivo - O objetivo deste estudo foi analisar as taxas de remissão perianal completa com a terapia combinada na doença de Crohn perianal fistulizante. Métodos - Trata-se de um estudo retrospectivo e observacional com portadores de doença de Crohn perianal fistulizante submetidos à terapia combinada provenientes de quatro centros de referência do Brasil. Foram analisadas as características de base dos pacientes, classificação de Montreal, medicamentos concomitantes, classificação das fístulas, ocorrência de remissão perianal completa e recorrência. Remissão perianal completa foi definida como ausência de drenagem das fístulas associada à retirada dos sedenhos. Discussão - Foram incluídos 78 pacientes, $44(55,8 \%)$ mulheres, com média de idade de $33,8( \pm 15)$ anos. A maior parte dos pacientes foi tratada com Infliximabe, 66,2\%, do que com Adalimumabe, 33,8\%. Fístulas complexas foram observadas em 52/78 (66,7\%) pacientes. Após um seguimento médio de 48,2 meses, 41/78 (52,6\%) pacientes apresentaram remissão perianal completa (IC 95\%: 43,5\%-63,6\%). Recorrência foi observada em quatro $(9,8 \%)$ pacientes (IC 95\%: 0,7\%-18,8\%) em um período médio de 74,8 meses para sua ocorrência. Conclusão - A terapia combinada trouxe resultados favoráveis e duradouros em portadores de doença de Crohn perianal fistulizante.

DESCRITORES - Doença de Crohn. Fator de necrose tumoral alfa. Fístula retal. 


\section{REFERENCES}

1. American Gastroenterological Association. AGA technical review on perianal Crohn's disease. Gastroenterology. 2003;125:1508-30.

2. Antakia R, Shorthouse AJ, Robinson K, Lobo AJ. Combined modality treatment for complex fistulating perianal Crohn's disease. Colorectal Dis. 2013;15:210-6.

3. Ardizzone S, Maconi G, Cassinotti A, Massari A, Porro GB. Imaging of perianal Crohn's disease. Dig Liver Dis. 2007;39:970-8.

4. Bernstein LH, Frank MS, Brandt LJ, Boley SJ. Healing of perianal Crohn's disease with metronidazole. Gastroenterology. 1980;79:357-65.

5. Colombel JF, Schwartz DA, Sandborn WJ, Kamm MA, D’Haens G, Rutgeerts P, et al. Adalimumab for the treatment of fistulas in patients with Crohn's disease. Gut. 2009;58:940-8.

6. Dewint P, Hansen BE, Verhey E, Oldenburg B, Hommes DW, Pierik M, et al. Adalimumab combined with ciprofloxacin is superior to adalimumab monotherapy in perianal fistula closure in Crohn's disease: a randomised, double-blind, placebo controlled trial (ADAFI). Gut. 2014;63:292-9.

7. El-Gazzaz G, Hull T, Church JM. Biological immunomodulators improve the healing rate in surgically treated perianal Crohn's fistulas. Colorectal Dis. 2012;14:1217-23.

8. Gaertner WB, Decanini A, Mellgren A, Lowry AC, Goldberg SM, Madoff RD, Spencer MP. Does infliximab infusions impact results of operative treatment for Crohn's perianal fistulas? Dis Colon Rectum. 2007;50:1754-60.

9. Hyder SA, Travis SP, Jewell DP, McC Mortensen NJ, George BD. Fistulating anal Crohn's disease: results of combined surgical and infliximab treatment. Dis Colon Rectum. 2006 Dec;49(12):1837-41.

10. Ingle SB, Loftus Jr EV. The natural history of perianal Crohn's disease. Dig Liver Dis. 2007;39:963-9.

11. Jones DW, Finlayson SRG. Trends in Surgery for Crohn's Disease in the Era of Infliximab. Annals of Surgery. 2010;25:307-12.

12. Khaikin M, Chowers Y, Zmora O. Perianal Crohn's disease. Isr Med Assoc J. 2007;9:163-8.
13. Ng SC, Plamondon S, Gupta A, Burling D, Swatton A, Vaizey CJ, Kamm MA. Prospective evaluation of anti-tumor necrosis factor therapy guided by magnetic resonance imaging for Crohn's perineal fistulas. Am J Gastroenterol. 2009;104:2973-86.

14. Pearson DC, May GR, Fick GH, Sutherland LR. Azathioprine and 6-mercaptopurine in Crohn's disease: a meta analysis. Ann Intern Med. 1995;123:132-42.

15. Present DH, Korelitz BI, Wisch N, Glass JL, Sacher DB, Pasternack BS. Treatment of Crohn's disease with mercaptopurine: a long-term, randomized, double-blind study. N Engl J Med. 1980; 302:981-7.

16. Present DH, Rutgeerts P, Targan S, Hanauer SB, Mayer L, van Hogezand RA, et al. Infliximab for the treatment of fistulas in patients with Crohn's disease. $\mathrm{N}$ Engl J Med. 1999;340:1398-405.

17. Regueiro M, Mardini H. Treatment of perianal fistulizing Crohn's disease with infliximab alone or as an adjunct to exam under anesthesia with seton placement. Inflamm Bowel Dis. 2003;9:98-103.

18. Ruffolo C, Citton M, Scarpa M, Angriman I, Massani M, Caratozzolo E, Bassi Nicolo. Perianal Crohn's disease: is there something new? World J Gastroenterol. 2011;17:1939-46.

19. Sands BE, Anderson FH, Bernstein CN, Chey WY, Feagan BG, Fedorak RN, et al Infliximab Maintenance Therapy for Fistulizing. N Engl J Med. 2004;350:876-85.

20. Talbot C, Sagar PM, Johnston MJ, Finan PJ, Burke D. Infliximab in the surgical management of complex fistulating anal Crohn's disease. Colorectal Dis. 2005; 7:164-8.

21. Turunen U, Farkkila M, Seppala K. Long-term treatment of perianal or fistulous Crohn's disease with ciprofloxacin. Scand J Gastroenterol Suppl. 1989;24:144.

22. Van Assche G, Dignass A, Reinisch W, van der Woude CJ, Sturm A, De Vos M, Guslandi M, Oldenburg B et al. The second European evidence-based Consensus on the diagnosis and management of Crohn's disease: Special situations. J Crohns Colitis. 2010;4:63-101.

23. Van Assche G, Vanbeckevoort D, Bielen D, Coremans G, Aerden I, Noman M, et al. Magnetic resonance imaging of the effects of infliximab on perianal fistulating Crohn's disease. Am J Gastroenterol. 2003;98:332-9.

24. Vermeire S, Van Assche G, Rutgeerts P. Perianal Crohn's disease: classification and clinical evaluation. Dig Liver Dis. 2007;39:959-62. 